\title{
Teor de cálcio e magnésio e parâmetros de acidez do solo em lavouras arrozeiras de Santa Catarina
}

\author{
Fabiana Schmidt ${ }^{1}$
}

\begin{abstract}
Resumo - O objetivo deste trabalho foi avaliar a disponibilidade de Ca e Mg, a saturação por bases (V\%) e os parâmetros de acidez do solo em lavouras arrozeiras de Santa Catarina para subsidiar as recomendações de calagem. As variáveis para o banco de dados foram resgatadas de 2.464 análises de solo de quatro safras agrícolas (2012-2015), oriundas de lavouras localizadas em sete regiões orizícolas: Alto, Médio e Baixo Vale do Itajaí, Litoral Norte, Araranguá, Criciúma e Tubarão. Os atributos do solo foram enquadrados em faixas de interpretação (classes) estabelecidas em manuais. Os solos das lavouras arrozeiras de SC são predominantemente ácidos. Nas regiões de Criciúma, do Baixo e do Médio Vale do Itajaí mais de $50 \%$ das análises indicaram teores baixos de Ca. Nas regiões de Araranguá e Litoral Norte, de 30\% a 40\% delas apresentaram resultados similares. Para o sistema pré-germinado, a maioria das lavouras das regiões de Tubarão, Araranguá, Alto Vale e Litoral Norte necessitariam de quantidades inferiores a $200 \mathrm{~kg} \mathrm{ha}^{-1}$ de calcário dolomítico PRNT 100\% aplicados como fonte de Ca e Mg.
\end{abstract}

Termos de indexação: calagem; saturação por bases; pH em água; arroz irrigado.

\section{Calcium and magnesium content and soil acidity parameters in rice fields of Santa Catarina State}

Abstract - The objective of this research was to evaluate Ca and Mg availability, base saturation (V\%) and soil acidity parameters of rice fields in Santa Catarina (SC) to subsidize liming recommendations. The database was built with variables obtained from 2.464 soil samples analyzed during four agricultural crops cycles (2012-2015) in seven regions: Alto, Médio and Baixo Vale do Itajaí, Litoral Norte, Araranguá, Criciúma and Tubarão. The soil attributes were grouped in classes for interpretation according to limits established by current recommendation manuals. The soils of rice fields of SC are predominantly acidic. More than $50 \%$ of the soil samples from Criciúma, Médio and Baixo Vale do Itajaí regions, and 30-40\% of those from Litoral Norte and Araranguá regions, indicated low levels of Ca. The diagnosis indicated the necessity of soil acidity correction for the most soil analyzes, if the farmers' option is to sow the irrigated rice under dry soil conditions. For the pre-germinated system, most of the fields in the Tubarão, Araranguá, Alto Vale and Litoral Norte regions would require less than $200 \mathrm{~kg} \mathrm{ha}^{-1}$ of effective dolomitic limestone to supply $\mathrm{Ca}$ and $\mathrm{Mg}$.

Index terms: liming; base saturation; ph in water saturation; irrigated rice.

\section{Introdução}

O nível de fertilidade do solo é fator que interfere na produtividade da lavoura orizícola, juntamente com as condições climáticas do ano agrícola, a qualidade do manejo, o estado sanitário da cultura e o potencial genético dos cultivares utilizados (FAGERIA et al., 1995). A avaliação da fertilidade envolve os processos de amostragem e análise do solo, diagnóstico dos resultados e modelos de interpretação e de recomendação de corretivos e fertilizantes. Assim, o diagnóstico da acidez e disponibilidade de nutrientes em solos representativos das lavouras arrozeiras é fundamental para a implementação de estratégias de adubação mais apropriadas para o arroz irrigado.

No estado de Santa Catarina, as lavouras arrozeiras ocupam uma área cultivada de 148.316 hectares, com produção de 1.176,234 toneladas e rendimento médio de $7.931 \mathrm{~kg} \mathrm{ha}^{-1}$ $\left(158,6\right.$ sacos ha-1) $^{-1}$ (CEPA, 2017). As lavouras de arroz do estado apresentam grande diversidade nos tipos de solos, o que torna relevante conhecer a fertilidade destes de forma regionalizada. Predominam solos das classes Gleissolo, Cambissolo, Organossolo, Neossolo, Espodossolo e manguezais que englobam os alagadiços e Gleissolos sálicos e tiomórficos (PINTO et al., 2004). Estes solos são formados por diferentes tipos de sedimentos, o que os torna muito heterogêneos, resultando em compor- tamentos distintos quando submetidos ao processo produtivo.

Além disso, o solo das lavouras é inundado para o cultivo do arroz irrigado, o que desencadeia uma série de mudanças químicas e eletroquímicas, que afetam a disponibilidade de nutrientes e, consequentemente, o crescimento da cultura. O alagamento do solo proporciona a formação de um ambiente anaeróbio e promove o processo de redução dos compostos oxidados, o que eleva o $\mathrm{pH}$ do solo pelo consumo de prótons $\mathrm{H}^{+}$ (VAHL \& LOPES, 1998).

As recomendações de calagem para o arroz irrigado consideram a elevação natural do $\mathrm{pH}$ que ocorre após o alagamento do solo. Assim, o manejo da água da irrigação no estabelecimento da cul- 
tura e a disponibilidade de Ca e Mg no solo são os principais fatores considerados ao se proporem recomendações de calagem para os sistemas de produção de arroz irrigado (SILVA \& RANNO, 2005).

No sistema de semeadura do arroz irrigado em solo seco, recomenda-se calagem para atenuar os efeitos da acidez no período em que as plantas permanecem no solo sem alagamento. Para tal, utiliza-se o $\mathrm{pH}$ em água inferior a 5,5 (exceto para solos com saturação por bases $\geq 65 \%$ e saturação por Al na CTC < 10\%) como critério de definição da necessidade de calagem, e o índice SMP para elevação do pH em água a 5,5 como critério para estabelecer a dose de calcário. No cultivo do arroz em sistema pré-germinado, onde o alagamento ocorre antes da semeadura e a elevação natural do $\mathrm{pH}$ coincide com a maior parte do ciclo da cultura, a calagem não é recomendada para neutralizar a acidez do solo (CQFS RS/SC, 2016; SOSBAI, 2016).

O calcário pode ser utilizado como fonte de Ca e Mg em ambos os sistemas de produção. A recomendação de aplicar calcário para essa finalidade no cultivo em sistema pré-germinado é feita quando a análise de solo indica saturação por bases $\leq 40 \%$, exceto quando Ca e Mg trocáveis forem superiores a 4,0 e $1,0 \mathrm{cmol}_{\mathrm{c}} \mathrm{dm}^{-3}$, respectivamente. Quando necessário, o calcário a aplicar é estimado pela diferença entre a saturação por bases a ser atingida ( $V=40 \%$ ) e a atual, considerando também a capacidade de troca de cátions do solo a pH 7,0 (CTC potencial).

Em relação à cultura do arroz irrigado, existem diferentes critérios para estabelecer a dose de calcário a ser aplicada. São escassas as informações disponíveis sobre a disponibilidade de Ca e Mg nos solos das lavouras e sobre a resposta à calagem em ambos os sistemas de cultivo na produção de arroz irrigado.

Este trabalho objetivou avaliar a disponibilidade de Ca e Mg trocáveis, a saturação por bases (V\%) e os parâmetros de acidez em solos de lavouras arrozeiras de Santa Catarina e fornecer subsídios às recomendações de calagem estabelecidas para os sistemas de cultivo de arroz irrigado.

\section{Materiais e Métodos}

\section{Abrangência do trabalho e banco de dados}

A pesquisa foi realizada coletando informações das análises de solo existentes nos escritórios municipais da Empresa de Pesquisa Agropecuária e Extensão Rural de Santa Catarina (Epagri), cooperativas e produtores rurais. $\mathrm{O}$ banco de dados contém 2.464 análises de solo de lavouras arrozeiras comerciais, coletadas em quatro safras agrícolas (2012-2015). Elas representam a variabilidade dos solos de municípios produtores de arroz irrigado no estado de Santa Catarina. Os municípios foram agrupados em sete regiões geográficas: Alto, Médio e Baixo Vale do Itajaí, Litoral Norte, Araranguá, Criciúma e Tubarão. O tamanho $(\mathrm{n})$ das amostras de análises de solo resgatadas para cada região arrozeira foi: Araranguá $n=526$, Alto Vale $n=524$, Baixo Vale $n=123$, Criciúma $n=275$, Médio Vale $n=203$, Litoral Norte $n=415$ e Tubarão $n=398$ ).

Os municípios de Araranguá, Ermo, Jacinto Machado, Maracajá, Meleiro, Morro Grande, Passo de Torres, Praia Grande, Santa Rosa do Sul, São João do Sul, Sombrio, Timbé do Sul e Turvo compuseram a região Araranguá. Na região Criciúma foram incluídos os municípios de Cocal do Sul, Criciúma, Forquilhinha, Içara, Morro da Fumaça, Nova Veneza, Siderópolis, Treviso e Urussanga. A região Tubarão compreendeu os municípios de Capivari de Baixo, Garopaba, Gravatal, Imaruí, Imbituba, Jaguaruna, Laguna, Pescaria Brava, Sangão, Treze de Maio, Tubarão, Palhoça e Paulo Lopes. Os municípios de Araquari, Barra Velha, Corupá, Garuva, Guaramirim, Itapoá, Jaraguá do Sul, Joinville, Massaranduba, São Francisco do Sul e Schroeder corresponderam à região Litoral Norte. A região Baixo Vale do Itajaí compreendeu os municípios de Balneário Piçarras, Camboriú, Ilhota, Itajaí, Itapema, Navegantes, Porto Belo e São João do Itaperiú. A região Médio Vale do Itajaí compreendeu os municípios de Apiúna, Ascurra, Benedito Novo, Blumenau, Brusque, Doutor Pedrinho, Gaspar, Guabiruba, Indaial, Luiz Alves, Rio dos Cedros, Rodeio e Timbó. A re- gião do Alto Vale do Itajaí compreendeu os municípios de Agronômica, Braço do Trombudo, Alfredo Wagner, Ibirama, Laurentino, Lontras, Mirim Doce, Pouso Redondo, Presidente Getúlio, Rio do Campo, Rio do Oeste, Rio do Sul, Salete, Trombudo Central e Taió.

\section{Índices de fertilidade do solo e normas para o enquadramento em faixas de interpretação}

O banco de dados foi composto pelas análises de solo provenientes de amostras de camada de $0-20 \mathrm{~cm}$ de profundidade. As variáveis de fertilidade do solo compiladas foram $\mathrm{pH}$ em água, índice SMP, teores de $\mathrm{Ca}, \mathrm{Mg}$ e Al trocáveis e a porcentagem de saturação por bases (V\%). Os valores das variáveis foram obtidos de análises de solo realizadas em laboratórios credenciados à Rede oficial de laboratórios de análise de solo e de tecido vegetal dos estados do Rio Grande do Sul e de Santa Catarina (ROLAS RS/SC).

$\mathrm{O}$ enquadramento dos atributos químicos do solo nas faixas de interpretação (classes) foi efetuado de acordo com os limites estabelecidos pelos principais manuais técnicos utilizados nos dois estados representados pela instituição, com o auxílio de programas computacionais. Os valores de $\mathrm{pH}$ em água foram enquadrados em cinco faixas: < 4,5, 4,5-5,0, 5,1-5,4, 5,5-6,0 e $>6,0$, que correspondem às classes extremamente baixo, muito baixo, baixo, médio e alto, respectivamente. Os valores de índice SMP foram enquadrados em cinco faixas: $\leq 5,1,5,2-5,6,5,7-6,2$, $6,3-6,6$ e $>6,6$. A esses valores correspondem as recomendações de $\geq 6,0$; 5,3-3,2; 2,8-1,0; 0,8-0,2; e 0 (zero) toneladas de calcário por hectare para elevar o pH do solo a 5,5 (CQFS- RS/SC, 2016; SOSBAI, 2016). Estas recomendações foram estabelecidas para calagem do arroz irrigado no sistema de semeadura em solo seco.

Os valores de saturação por bases foram agrupados em cinco faixas: $\leq 20$; 21-40; 41-60; $61-80$ e > 80\%. Os teores de $\mathrm{Ca}$ e $\mathrm{Mg}$ foram enquadrados em três classes cada um: $<2,0 ; 2,0-4,0$ e $>4,0 \mathrm{cmol}_{\mathrm{c}} \mathrm{dm}^{-3}$ para Ca trocável; < 0,5; $0,5-1,0$ e $>1,0 \mathrm{cmol}_{\mathrm{c}} \mathrm{dm}^{-3}$ para $\mathrm{Mg}$ trocável. Esses intervalos correspondem, ' 
respectivamente, às faixas de teores baixo, médio e alto (CQFS- RS/SC, 2016). Os teores de Al trocável foram enquadrados em 5 faixas: $\leq 0,20 ; 0,21-0,50$; 0,51-1,00; 1,00-2,00 e $>2,00 \mathrm{cmol}_{\mathrm{c}} \mathrm{dm}^{-3}$, que correspondem, respectivamente, às classes muito baixo, baixo, médio, alto e muito alto.

As recomendações de calagem para fornecimento de Ca e Mg no sistema de cultivo pré-germinado de arroz foram distribuídas nas faixas de necessidade: $>6,0 ; 6,0-3,1 ; 3,0-1,0 ; 0,9-0,2$; e < 0,2 toneladas de calcário dolomítico PRNT $100 \%$ por hectare para atingir $40 \%$ de saturação por bases (CQFS RS/SC, 2016; SOSBAI, 2016).

As variáveis avaliadas foram submetidas a distribuição de frequência e agrupadas em classes com limites superiores e inferiores definidos, atendendo às faixas de interpretação estabelecidas pela pesquisa. Os dados foram apresentados separadamente para cada região orízicola. A distribuição de frequência dos atributos químicos do solo foi efetuada pelo programa Genes (CRUZ, 2001). A estatística descritiva foi calculada em planilha eletrônica do Microsoft Excel.

\section{Resultados e Discussão}

\section{Parâmetros de acidez do solo: pH em água, índice SMP, teor de Al trocável e saturação por bases}

As análises de solo das lavouras arrozeiras de Santa Catarina mostraram que os solos são ácidos, com o predomínio de valores de $\mathrm{pH}$ em água entre 4,5-5,0 (muito baixo) e 5,1-5,4 (baixo). As análises das regiões Araranguá, Criciúma, Alto, Baixo e Médio Vale do Itajaí e Litoral Norte possuem de $86,2 \%$ a $94,9 \%$ de $\mathrm{pH}$ inferiores a 5,5. A Região Tubarão apresentou o menor percentual de análises (77\%) com pH em água inferior a 5,5 (Figura 1 A).

Embora os solos das lavouras arrozeiras sejam ácidos, para os sistemas de cultivo de arroz irrigado, nos quais a planta está sob condições de solo inundado desde o início do ciclo (sistema pré-germinado e transplante de mudas), não é recomendada a calagem com a finalidade de corrigir a acidez do solo (CQFS- RS/SC, 2016; SOSBAI, 2016).
Em solo alagado, a elevação do pH ocorre naturalmente como consequência do processo de redução do solo, atingindo valores de $\mathrm{pH}$ próximos de 6,0 após quatro a seis semanas de inundação (SILVA \& RANNO, 2005).

A região Alto Vale do Itajaí foi a que apresentou a maior frequência de valores acima de $1 \mathrm{cmol}_{\mathrm{c}} \mathrm{dm}^{3}$ de $\mathrm{Al}^{3+}$ (71,9\% das análises) e, desses, 36,7\% se agruparam na classe muito alto $\left(>2 \mathrm{cmol}_{\mathrm{c}} \mathrm{dm}^{3} \mathrm{de} \mathrm{Al}^{3+}\right)$. As regiões Baixo Vale, Criciúma, Médio Vale e Litoral Norte apresentaram a maior frequência de análises de solo (33 a 42\%) na faixa de 1 a $2 \mathrm{cmol}_{\mathrm{c}} \mathrm{dm}^{3}$ de $\mathrm{Al}^{3+}$, considerado alto teor. As análises da região Araranguá apresentaram $26,7 \%$ e $29,4 \%$ das amostras nas faixas muito baixo e médio teor de $\mathrm{Al}^{3+}$, respectivamente. Apenas as análises de solos da região Tubarão apresentaram teores de $\mathrm{Al}^{3+}$ predominantemente nas faixas muito baixo $e$ baixo $\left(<0,5 \mathrm{cmol}_{c} \mathrm{dm}^{3}\right.$ de $\mathrm{Al}^{3+}$ ) (Figura 1B).

Na região Tubarão, os solos dominantes são perfis de Organossolos, que ocorrem em relevo plano e apresentam péssimas condições físicas quando drenados sem controle do lençol freático, pois sofrem o processo de subsidência, ou seja, acentuado rebaixamento do solo. Além disso, a maioria desses solos possui elevada acidez, com valores de $\mathrm{pH}$ de 3,5 a 4,5 (UBERTI, 2005). Entretanto, ao contrário do que ocorre em solos minerais, onde a acidez se deve ao alumínio trocável, nos Organossolos o pH está mais relacionado ao teor de ácidos orgânicos e à presença de sulfeto de ferro, além de outros compostos de enxofre oxidáveis (LEPSCH et al., 1990).

Os teores de Al nas análises de solos resgatadas na região Tubarão foram agrupados predominantemente nas faixas muito baixo e baixo, o que corrobora a hipótese de que a acidez nos Organossolos dessa região seja originada principalmente devido ao $\mathrm{H}^{+}$proveniente dos compostos orgânicos e da hidrólise de outros compostos, como os de enxofre (Figura 1B). O Al ${ }^{3+}$ é facilmente complexado por radicais orgânicos em solos com elevado teor de matéria orgânica, deixando de ser um problema para as plantas. Segundo Knoblauch (1997), embora a calagem seja necessária para a produção agrícola nesses solos, ela não é necessária para elevar o $\mathrm{pH}$ aos mesmos níveis preconizados para os solos minerais, especialmente devido à maior complexação do $\mathrm{Al}^{3+}$ pela matéria orgânica. Knoblauch (1997) também destaca que nos solos orgânicos não se verifica o fenômeno conhecido como autocalagem (elevação do pH para próximo do neutro ocasionada pela presença da água em solos minerais), por isso recomenda que nos solos orgânicos seja necessariamente realizada a calagem, mesmo nos cultivos irrigados por alagamento.

A aplicação de grandes quantidades de calcário nas lavouras de arroz da região Tubarão têm sido uma prática adotada pelos agricultores ao longo dos anos, o que pode ter colaborado para a diminuição da acidez e dos teores de Al nesses solos. Nesta região, ocorre a adoção da semeadura do arroz em solo seco devido às dificuldades no preparo do solo e na própria semeadura, causadas pela instabilidade física da estrutura dos Organossolos em condições de inundação. Assim, a semeadura do arroz em solo seco, aliada à acidez desses solos, contribuíram para o uso da correção da acidez com altas doses de calcário. Este manejo pode também ter favorecido os níveis mais baixos de Al nesses solos (Figura 1B).

Os solos das lavouras arrozeiras de Santa Catarina possuem predominância de valores de índice SMP entre 5,2 e 6,2 (Figura 1C). Dentre as regiões, Alto Vale do Itajaí e Tubarão apresentaram os maiores percentuais de análises $(28,2 \%$ e $25,6 \%$, respectivamente) agrupadas com índices SMP $\leq 5,1$ (Figura $1 C$ ). Cabe salientar que a diminuição dos valores do índice SMP é proporcional à acidez potencial do solo, que é constituída pelos íons $\mathrm{H}^{+}$e $\mathrm{Al}^{3+}$ presentes no solo. $O$ índice SMP é fator determinante da quantidade de corretivo necessária para neutralizar a acidez do solo em condições de cultivo do arroz irrigado com semeadura em solo seco.

Nas regiões arrozeiras Criciúma, Alto, Baixo e Médio Vale do Itajaí, aproximadamente $90 \%$ das análises de solo se enquadraram em valores de $\mathrm{V} \%<60$ (Figura 1D). Nessas regiões, as frequências de análises de solo agrupadas na faixa de $\mathrm{V} \%<20$ variaram de 21,2 a $28,8 \%$. Na região Litoral Norte, $80 \%$ 

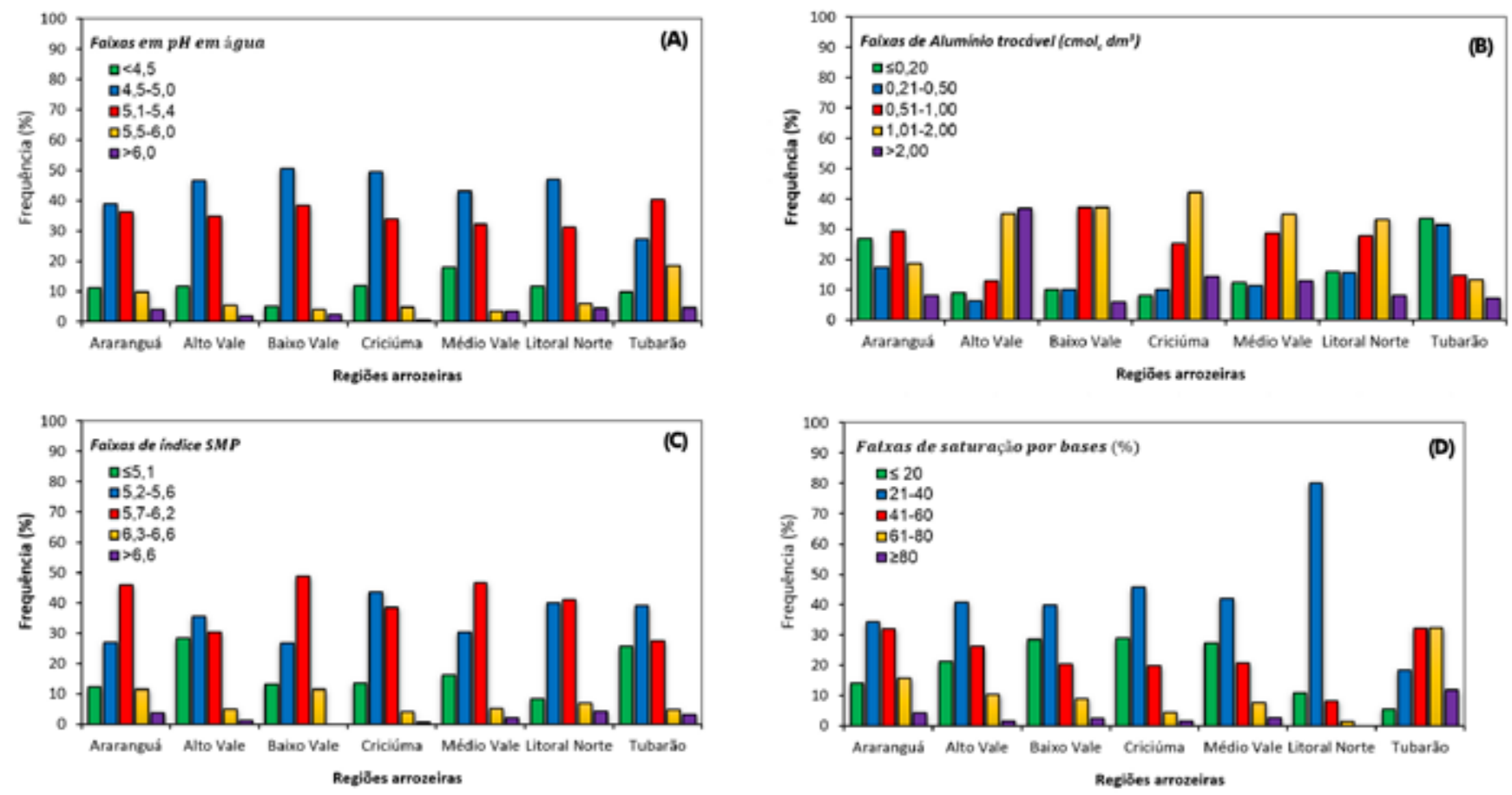

Figura 1. Distribuição relativa em faixas de interpretação dos valores de pH em água (A), teor de alumínio trocável (B), índice SMP (C) e saturação por bases (D) de solos de lavouras orizícolas das regiões produtoras de SC no período de 2012 a 2015

Figure 1. Relative distribution in ranges of interpretation of $\mathrm{pH}$ values in water $(A)$, exchangeable aluminum content (B), SMP index (C) and base saturation (D) of soils from rice fields in SC producing regions in period 2012 to 2015

das análises estavam na faixa de $\mathrm{V} \% 21$ a 40. Na região Araranguá predominaram solos com $\mathrm{V} \%$ de 21 a 40 (34,1\% das análises) e de 41 a 60\% (32\% das análises). Na região Tubarão predominaram solos agrupados nas faixas de V\% 41 a 60 (32,1\% das análises) e V\% de 61 a 80 (32,4\% das análises).

\section{Teores de cálcio e magnésio trocáveis}

Os baixos teores de Ca no solo predominaram nas análises oriundas de lavouras de arroz das regiões Baixo Vale (57,7\%), Criciúma (61,1\%) e Médio Vale (56,6\%). As regiões Araranguá, Litoral Norte e Alto Vale apresentaram, respectivamente, $35,3 \%$, 32,8 e 23,5\% das análises com teores baixos de $\mathrm{Ca}$. Por outro lado, a região Tubarão apresentou $76,3 \%$ das análises com teores altos de Ca $\left(>4 \mathrm{cmol}_{\mathrm{c}} \mathrm{dm}^{3}\right.$ ) (Figura $2 \mathrm{~A}$ ).

Estes teores provavelmente estão relacionados à ausência da aplicação de calcário para correção da acidez do solo devido ao cultivo realizado em sistema pré-germinado, com o alagamento antecipado do solo. Entretanto, os teores altos observados nas lavouras da região Tubarão podem estar diretamente rela- cionados com a calagem praticada nas lavouras onde há predominância de Organossolos.

Nos solos das lavouras arrozeiras predominaram teores de $\mathrm{Mg}$ altos (Figura 2B). Entretanto, mais de $20 \%$ das análises das regiões Araranguá, Criciúma, Baixo e Médio Vale do Itajaí e Litoral Norte apresentaram teores baixos de $\mathrm{Mg}\left(\leq 0,5 \mathrm{cmol}_{\mathrm{c}} \mathrm{dm}^{3}\right)$.

\section{Necessidade de calcário como fonte de Ca e Mg no sistema pré-germinado}

Simulando a recomendação de calagem como fonte de Ca e Mg para lavouras implantadas no sistema pré-germinado, verificou-se que $85 \%$ das análises da região Tubarão, $60 \%$ das análises da região Araranguá, $50 \%$ das análises da região Alto Vale do Itajaí e $47 \%$ das análises da região Litoral Norte necessitaram de quantidades inferiores a $200 \mathrm{~kg} \mathrm{ha}^{-1}$ de calcário dolomítico PRNT $100 \%$ ou não necessitaram da aplicação para suprir estes nutrientes (Figura 3A).

Foi diagnosticado que $41 \%$ das análises da região Criciúma, 32\% das análises da região Médio Vale do Itajaí, 30\% das análises da região Litoral Norte e $26 \%$ das análises da região Baixo Vale do Itajaí apresentaram necessidade da aplicação de 1 a 3 t ha $^{-1}$ de calcário dolomítico PRNT 100\% para aumentar a disponibilidade de Ca e Mg no solo.

Aplicações de doses altas de calcário ( $\geq 6 \mathrm{t} \mathrm{ha}^{-1}$ ) foram estabelecidas para apenas $6,3 \%$ das análises da região Alto Vale do Itajaí, 3,3\% das análises da região Araranguá e, no restante das regiões, ela representou menos de $2 \%$ das amostras.

Necessidade de calcário como corretivo de acidez em sistema de semeadura do arroz irrigado em solo seco

A simulação de recomendação de calcário como corretivo de acidez para a semeadura do arroz irrigado em condições de solo seco indicou que de 35 a 47,5\% das análises de lavouras das regiões Baixo e Médio Vale do Itajaí, Litoral Norte, Araranguá e Criciúma necessitariam da aplicação de 1 a $3 t$ ha $^{-1}$ de calcário dolomítico PRNT 100\% (Figura 3B). As análises indicaram necessidade de aplicação de doses de 3,2 a 5,3t ha-1 de calcário dolomítico PRNT 100\% em $42 \%$ das análises, na região Criciúma, • 

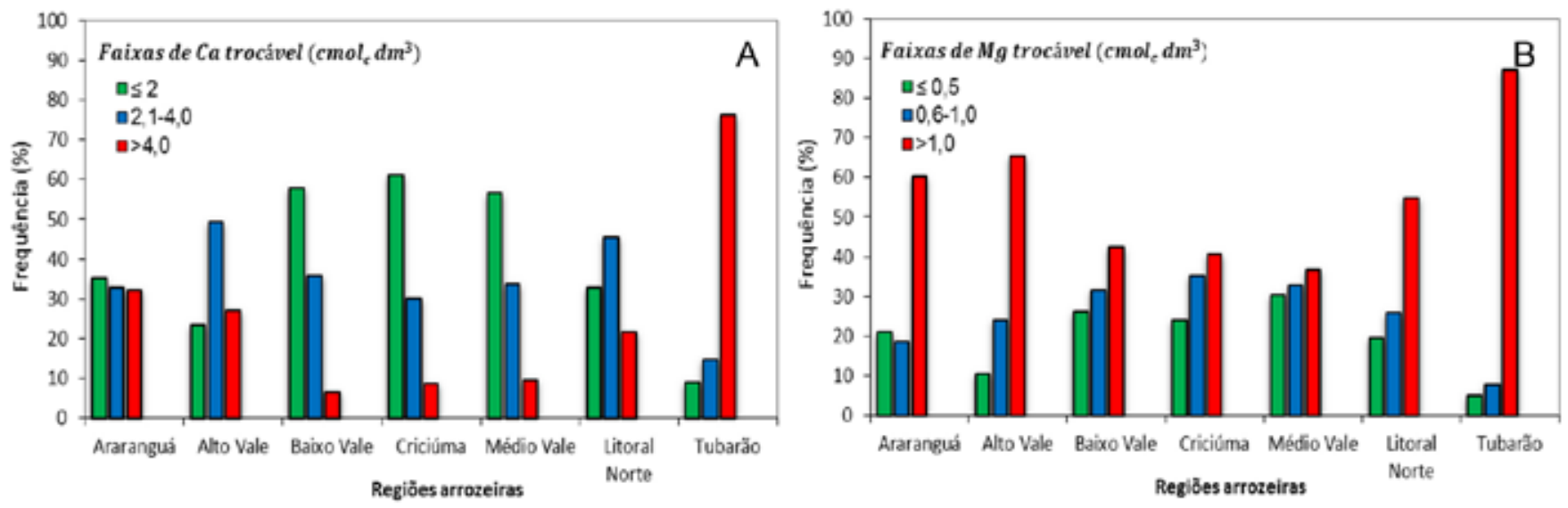

Figura 2. Distribuição relativa em faixas de interpretação dos teores de Ca (A) e Mg trocável (B) de solos de lavouras orizícolas de regiões produtoras de SC no período de 2012 a 2015

Figure 2. Relative distribution in ranges of interpretation of $\mathrm{Ca}(\mathrm{A})$ and exchangeable $\mathrm{Mg}(\mathrm{B})$ levels of soils from rice fields of SC producing regions in the period 2012 to 2015
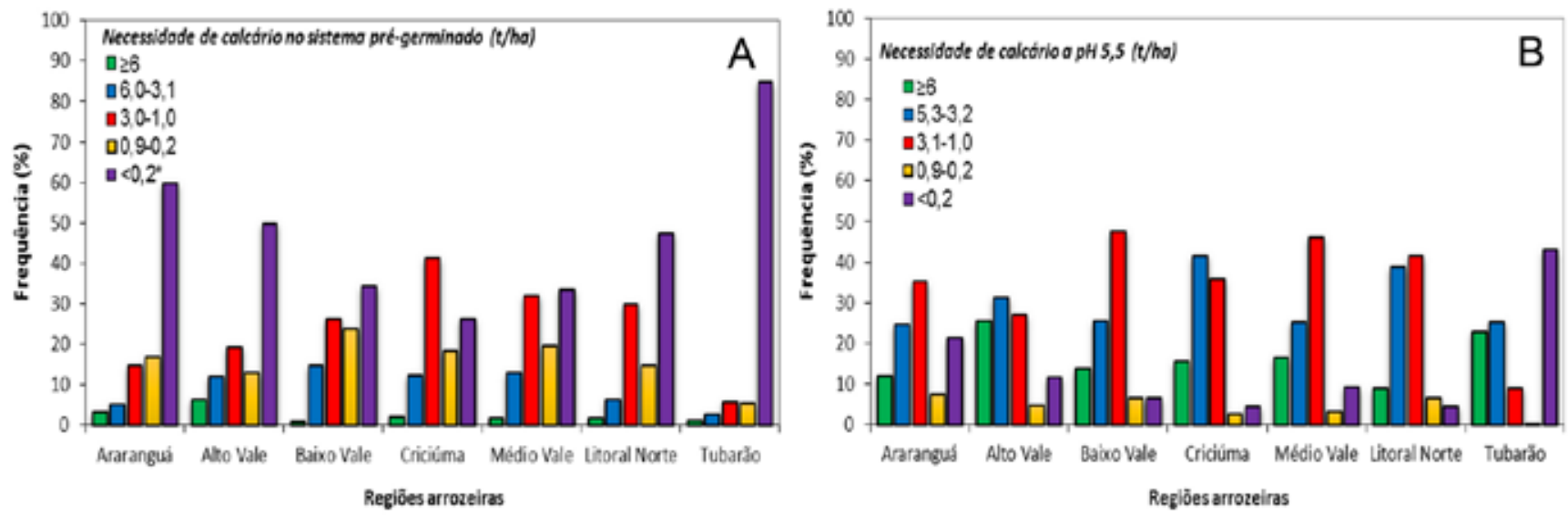

Figura 3. Distribuição em faixas de valores de necessidade de calcário dolomítico PRNT 100\% como fonte de Ca e Mg para o sistema prégerminado (A) e para elevar o pH do solo a 5,5 na semeadura do arroz irrigado em solo seco (B), conforme interpretação de análises de solo de regiões arrozeiras de SC no período de 2012 a 2015

Figure 3. Distribution of PRNT 100\% dolomitic limestone as a source of Ca and $\mathrm{Mg}$ for the pre-germinated system (A) and to raise soil pH to 5.5 in irrigated rice sowing on dry soil (B), according to interpretation of soil analyzes of rice regions of SC in the period 2012 to 2015

39\% das análises do Litoral Norte e, de 25 a 30\% nas demais regiões.

A aplicação de doses $\geq 6 \mathrm{t} \mathrm{ha}{ }^{-1}$ de calcário seriam recomendadas para a correção da acidez em $25 \%$ das análises da região Alto Vale e $23 \%$ das análises da região Tubarão. Haveria necessidade de aplicar doses inferiores a $1 \mathrm{t} \mathrm{ha}^{-1}$ de calcário ou até mesmo não aplicar calcário para a correção da acidez em $43,3 \%$ das análises oriundas da região Tubarão e em $28,5 \%$ das análises da região Araranguá. Para as demais regiões orízicolas, $85 \%$ a $93 \%$ das análises indicaram necessidade de aplicação de doses su- periores a 1 t ha-1 de calcário dolomítico PRNT $100 \%$ para correção da acidez do solo na semeadura do arroz em solo seco, conforme as recomendações estabelecidas (Figura $3 \mathrm{~B}$ ).

O presente levantamento de parâmetros da acidez e disponibilidade de $\mathrm{Ca}$ e $\mathrm{Mg}$ foi fundamental para o conhecimento geral da situação dos solos das lavouras orizícolas catarinenses. Embora os resultados mostrem um diagnóstico de alta frequência de teores baixos de Ca no solo para algumas regiões de Santa Catarina, necessita-se cautela nas recomendações de reposição deste nutriente, já que os padrões dos teores baixo, médio e alto deste nutriente estabelecidos na literatura não foram desenvolvidos para as condições de cultivo em solos alagados, caso do sistema pré-germinado. Assim, não se pode afirmar, a partir desses resultados, que adubações com este nutriente promoverão incrementos na produtividade da cultura do arroz, pois este tema necessita pesquisas específicas para melhor fundamentação. O diagnóstico da fertilidade dos solos das lavouras orizícolas em Santa Catarina feito neste trabalho constitui-se em forma de avaliação do 
panorama atual e não de recomendação. São necessários estudos posteriores para testar e comprovar a eficiência da correção dos teores de Ca nos solos de lavouras orízicolas conduzidas em sistema de cultivo pré-germinado.

\section{Conclusões}

Os solos das lavouras arrozeiras de Santa Catarina são predominantemente ácidos. À exceção da região de Tubarão, predominam teores baixos e médios de Ca, saturação por bases $\leq 40 \%$ e teores altos de Al nas lavouras arrozeiras.

Nas regiões Tubarão, Araranguá, Alto Vale do Itajaí e Litoral Norte, predominam áreas com solos que necessitam menores doses de calcário ou mesmo sem necessidade da aplicação deste como fonte de $\mathrm{Ca}$ e $\mathrm{Mg}$ no cultivo do arroz em sistema pré-germinado.

\section{Agradecimentos}

Aos extensionistas rurais da Epagri e à Empresa Plantar Serviços Agronômicos Ltda - Tubarão, que gentilmente colaboraram no resgate das análises de solo das lavouras arrozeiras.

\section{Referências Bibliográficas}

SANTA CATARINA. Centro de Socioeconomia e Planejamento Agrícola. Boletim Agropecuário no 50, de 15 de julho de 2017. Florianópolis: Epagri/Cepa, 2017, 54p.

CQFS-RS/SC- COMISSÃO de química e fertilidade do solo - RS/SC. Manual de calagem e adubação para os Estados do Rio Grande do Sul e Santa Catarina. 11ed. Santa Maria: Sociedade Brasileira de Ciência do Solo - Núcleo Regional Sul, 2016, 376p.

CRUZ, C.D. Programa GENES - versão windows. Aplicativo computacional em Genética e Estatística. 1 ed. Viçosa: Editora UFV, 2001. v.1. 648p.

FAGERIA, N.K.; SANTANA, E.P.; MORAIS, O.P. de. Resposta de genótipos de arroz de sequeiro favorecido à fertilidade do solo. Pesquisa Agropecuária Brasileira, Brasília, DF, v.30, n.9, p.1155-1161, 1995.

LEPSCH, I.F.; QUAGGIO, J.A.; SAKAI, E.; CAMARGO, O.A.; VALADARES, J.M.A.S. Caracterização, classificação e manejo agrícola de solos orgânicos do vale do Rio Ribeira de Iguape, SP. Campinas, Instituto Agronômico de Campinas, 1990. 58p. (Boletim Técnico, 131).

KNOBLAUCH, R. Solos orgânicos: aspectos gerais e recomendações preliminares de adubação e calagem para o arroz irrigado. Florianópolis: Epagri, 1997. 25p. (Boletim técnico, 91).

PINTO, L.F.S.; LAUS NETO, J.A.; PAULETTO, E.A. Solos de várzea do Sul do brasil cultivados com arroz irrigado. In: GOMES, A.S.; MAGALHÃES JÚNIOR A. M. (Eds.) Arroz Irrigado no Sul do Brasil. Brasília, DF: Embrapa Informação Tecnológica, 2004. p.75-96.

SILVA, L.S.; RANNO, S.K. Calagem em solos de várzea e a disponibilidade de nutrientes na solução do solo após o alagamento. Ciência Rural, Santa Maria, v.35, n.5, p.10541061, 2005.

SOCIEDADE SUL-BRASILEIRA DE ARROZ IRRIGADO. Arroz irrigado: recomendações técnicas da pesquisa para o sul do Brasil. Pelotas: Sociedade Sul-Brasileira de Arroz Irrigado, 2016. 200p.

UBERTI, A.A.A. Santa Catarina: Proposta de divisão territorial em Regiões Edafoambientais Homogêneas. 185f. Tese (Doutorado em Engenharia Civil)-Universidade Federal de Santa Catarina, Florianópolis, 2005.

VAHL, L.C.; LOPES, S.I.G. Nutrição de plantas. In: PESQUE, S.T.; NEDEL, J.L.; BARROS, A.C.S.A. (Eds). Produção de arroz irrigado. Pelotas: Editora e Gráfica Universitária, 1998. p.149-206.

\section{Nấ deire sua consciência escorrer pelo ralo: preserve a água e evite o desperdício.}
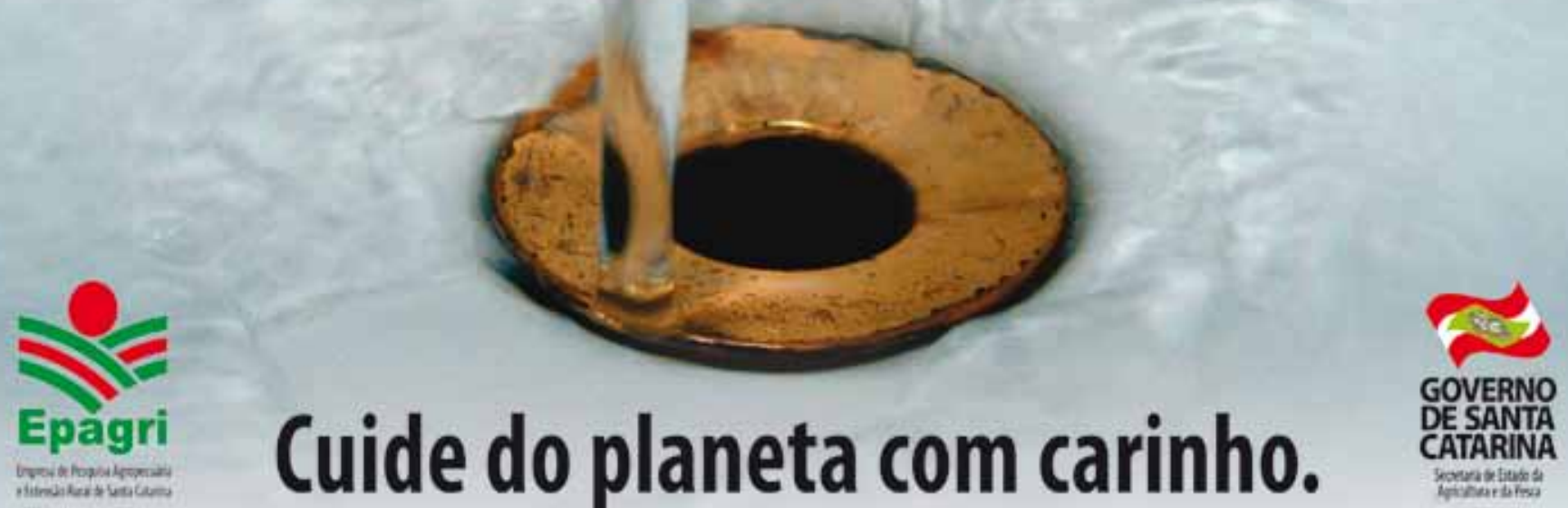